УAK 159.972

\title{
Переедание как способ регуляции эмоциональной сферы людей с синдромом нервной булимии очистительного типа
}

\author{
Юлия В. Свиткевич ID \\ Южный фредеральный университет, г. Ростов-на-Аону, Россия \\ svitkevich@sfedu.ru
}

\begin{abstract}
Аннотация
В статье рассматривается эмоционально-регулятивная функция перееАания у АюАей с Синаромом нервной булимии. Во введении автором раскрывается актуальность темы, которая определяется распространенностью расстройств пищевого поведения - в частности, нервной булимии. Новизна исслеАования заключается в рассмотрении поведенческой модели «переедание - очищение» в качестве регулятора эмоций на основе митературы.

В «Теоретическом обосновании» автором рассматриваются работы российских и иностранных авторов по следующим направлениям: определение нервной булимии; проявление и специфические симптомы; влияние на образ жизни приступов переедания и очищения; траектория развития заболевания, социальные и психологические аспекты.

В разделе «Результаты и их обсужление» автор акцентирует внимание на исслеАованиях, которые полтвержАают осознанность в выборе перееАания, не исключая импульсивный эмоциональный аспект поведения. Автор отмечает, что само компенсаторное поведение сопровождается определенными эмоциональными состояниями. Разграничивается поведение больных нервной анорексией, нервной булимией и компульсивным перееланием. В заключение Аелаются выводы о том, что: 1) жизнь больного нервной булимией имеет определенную цикличность: эпизоды самоконтроля сменяются перееАанием, что стимулирует еще больший самоконтроль и эмоциональное напряжение - чувство вины; 2) особенностью нервной булимии, в отличие от Аругих расстройств пищевого повеАения, является компенсаторное поведение, которое может быть предотвращено в определенный момент; 3) переедание выступает в качестве эмоционального регулятора. Автором полчеркивается важность Аальнейших исслеАований эмоциональной сореры и побужАений к перееданию и очистительному поведению больных нервной булимией, а также необходимость создания психотерапевтических и психодиагностических методик.
\end{abstract}


МЕДИЦИНСКАЯ ПСИХОЛОГИЯ

\title{
КАючевые слова
}

нервная булимия, расстройство пищевого поведения, причины переедания, переедание, очищение, компенсаторное поведение, эмоциональная сфрера, выбор, эмоциональная компенсация, импульсивность

\section{Аля цитирования}

Свиткевич, Ю. В. (2021). Переелание как способ регуляции эмоциональной сореры АюАей с синАромом нервной булимии очистительного типа. Северо-Кавказский психологический вестник, 19(1), 5-20. https://doi.org/10.21702/ncpb.2021.1

Scientific review

https://doi.org/10.21702/ncpb.2021.1

UDC 159.972

\section{Overeating as a Method of Emotional Regulation Among People With Purging Bulimia Nervosa}

\author{
Julia V. Svitkevich (iD) \\ Southern Federal University, Rostov-on-Don, Russia \\ svitkevich@sfedu.ru
}

\begin{abstract}
The article contains the information on the emotional regulation function of overeating among people with bulimia nervosa. In the introduction the author reveals the importance of the topic that is defined by the eating disorders (including bulimia nervosa) spreading. The novelty of the work is that basing on the scientific literature the author investigates the behavioral "binge-purge" pattern as an emotional controller. In the Theoretical Basis part the author reviews Russian and foreign papers to get the information about the definition of bulimia nervosa; its manifestation and specific symptoms; the influence binging and purging have on the way of living; its development trajectory; its social and psychological aspects.

In the Results and Discussion part the author is focused on studies that prove the consciousness of overeating choice, yet taking the impulsive emotional aspect into consideration. The author notes that this compensatory behavior is connected with the particular emotional states. The author distinguishes anorexia nervosa, bulimia nervosa, and compulsive overeating. In conclusion the author enlists next statements: 1) the life of the patient with bulimia nervosa is cyclic, self-control periods change to overeating, that provoke harder self-control and emotional tense resulting in guilt; 2) the peculiarity of bulimia nervosa is that, unlike other eating disorders, it is connected with compensatory behavior pattern that can be prevented in some special moment; 3) overeating acts as emotional controller. The author accentuates the importance
\end{abstract}


of further investigations in the field of emotions and also "binge-purge" motivations among those who suffer of bulimia nervosa, and then the author supposes that special psychotherapeutic and psychodiagnostic methods should be created.

\section{Keywords}

bulimia nervosa, eating disorder, causes of overeating, binge, purge, compensatory behavior, emotions, choice, emotional compensation, impulsiveness

\section{For citation}

Svitkevich, Ju. V. (2021). Overeating as a method of emotional regulation among people with purging bulimia nervosa. Severo-Kavkazskii psikhologicheskii vestnik (North-Caucasian Psychological Bulletin), 19(1), 5-20. https://doi.org/10.21702/ncpb.2021.1 (in Russ.).

\section{Введение}

С вхождением в цифровую эпоху образ жизни современного человека претерпел кардинальные изменения: положение тела стало преимущественно сидячим, деятельность - интеллектуальной. Соответственно, от недостатка физической активности, но с неизменным количеством потребляемых калорий возрастает частота возникновения ожирения. По данным ВОЗ, в период с 1980 по 2008 гг. во всем мире число людей с ожирением увеличилось почти в два раза (Панькив, 2013).

На борьбу с ожирением вступила пропаганда фитнеса, диетического питания и всего, что связано или не совсем связано со здоровым образом жизни. Действительно, если официальные рекомендации ВОЗ, специалистов в сфере медицины и могут нивелировать прогрессирующее ожирение, то рекомендации людей, не просвещенных в работе человеческого организма, могут лишь навредить. Одна из таких рекомендаций - голодание.

Волна моды на похудение имела как положительное воздействие на общество, так и отрицательное - изменение пищевого поведения современного человека индустриальных и постиндустриальных обществ. Это стимулирует, в свою очередь, возникновение пищевых расстройств (Самсонова, 2015).

Нервная булимия (НБ) - психическое расстройство, характеризующееся эпизодами переедания и похудения. Отличием от компульсивного переедания (КП) является компенсаторное поведение булимика - действия, направленные на ликвидацию съеденного.

Актуальность исследования нервной булимии обусловлена развивающейся пропагандой в Интернете «идеалов» внешности, худобы, романтизацией булимии и анорексии (Маслов, Гнатюк и Самыгин, 2018).

Тенденции моды возвращаются к 80-90-м гг. XX в., когда было популярно не просто стройное, а худое тело. Зачастую модели превосходили себя: доводили 
себя до анорексии и дистрофии. Как раз и возрастать упоминания булимии в научной литературе стали несколько раньше - еще с 80-х гг. XX в. (Simpson, Al-Mufti, Andersen, \& DePaulo, 1992). Другой тенденцией современного мира становится компьютеризация. Виртуальный мир позволяет объединяться и формировать тематические сообщества, которые могут как помочь, так и популяризировать, драматизировать и идеализировать заболевание (Ильина, 2020). Среди социологических факторов возникновения расстройства пищевого поведения частыми являются давление со стороны общества, пропаганда худобы и идеального телосложения, а также влияние семьи и социального окружения, тяжелые переживания или жизненные проблемы (Панюкова, 2019).

Согласно исследованиям, посвященным нервной булимии, это довольно распространенная проблема. Однако данные о распространенности могут разниться не только в зависимости от культурных особенностей стран, но и внутри государства. Так, например, среди женщин Соединенных Штатов Америки и Канады распространенность нервной булимии оценивается в диапазоне от 1 \% до 4,2 \% (Hoek \& van Hoeken, 2003).

Причинами переедания при нервной булимии выступают как физиологические аспекты (долгое недоедание снижает концентрацию в крови необходимых веществ, вызывает пищевое поведение на уровне рефлексов), так и психологические, психосоциальные (установки, цели, ценности, идеалы, мотивация; давление со стороны общества, пропаганда худобы).

Целью данного исследования является рассмотрение переедания в качестве способа эмоциональной регуляции у людей, страдающих нервной булимией.

\section{Теоретическое обоснование}

Термин «нервная булимия» (НБ) был впервые введен Дж. Расселом в 1979 г. По его мнению, заболевание было распространено среди студенток университета (Russell, 1979). Однако ученый рассматривал булимию как «переходную стадию» перед нервной анорексией. Им и было отмечено характерное для 1-го типа булимиков поведение: чрезмерное переедание и вызывание рвоты (Медведев и Лоскучерявая, 2013).

Основным признаками, позволяющими поставить диагноз «нервная булимия», являются:

1) многократное вызывание рвоты, голодание, применение слабительных, мочегонных средств и клизм, чрезмерные физические упражнения во избежание прибавки массы тела;

2) периодические эпизоды переедания;

3) оба перечисленных выше симптома должны проявляться в среднем дважды в неделю в течение трех месяцев;

4) преувеличенное влияние фигуры и массы тела на самооценку; 
5) отсутствие диагноза нервной анорексии (Мэйа, Халми, Лопез-Ибор и Сарториус, 2006).

В России НБ клинически диагностируется психиатрами согласно критериям, указанным в международной классификации болезней 10-го пересмотра (МКБ-10). В источнике НБ определяется как «синдром, характеризующийся повторными приступами переедания и выраженным беспокойством по поводу контроля за массой тела» (Международная статистическая классификация..., 2003, с. 126).

B DSM-V, в отличие от МКБ-10, уточняются также клинические подтипы НБ: очистительный (компенсаторное поведение ориентировано на избавление от съеденного с помощью рвоты, диуретических и слабительных средств, клизм); неочистительный (компенсаторное поведение проявляется в последующем воздержании от еды (пост), чрезмерных физических нагрузках). Очистительный тип НБ представляет большую опасность, поскольку от приема слабительных и диуретиков нарушается электролитный баланс, от рвоты функционирование органов ЖКТ. Такие люди обладают меньшей массой тела, чем пациенты с неочистительным типом.

Люди с синдромом нервной булимии по-разному воспринимают количество пищи. Для одних даже маленький кусочек «запрещенной» пищи может вызвать непреодолимое желание вырвать, другие же переедают настолько, что становится трудно дышать, и очищение становится необходимым даже физиологически.

В таблице 1 представлено сравнение расстройств пищевого поведения. Важно отличать нервную булимию от других видов РПП. Ключевым отличием является компенсаторное поведение, заключающееся в действиях, направленных на избавление от принятой пищи.

\begin{tabular}{|ccc|}
\hline Таблица 1 & \\
Сравнительные характеристики расстройств пищевого поведения \\
\hline Анорексия & Булимия & Компульсивное \\
Низкая масса & Нормальная или повышенная & Преедание \\
тела, десрицит & масса тела & массы тела \\
Пациенты редко & Ищут помощи, могут обращаться & Пациенты \\
обращаются & к специалисту, охотнее илут & обращаются \\
к специалисту & на контакт. Положительный ответ & к специалисту \\
& примерно у 60\% пациентов &
\end{tabular}


МЕДИЦИНСКАЯ ПСИХОЛОГИЯ

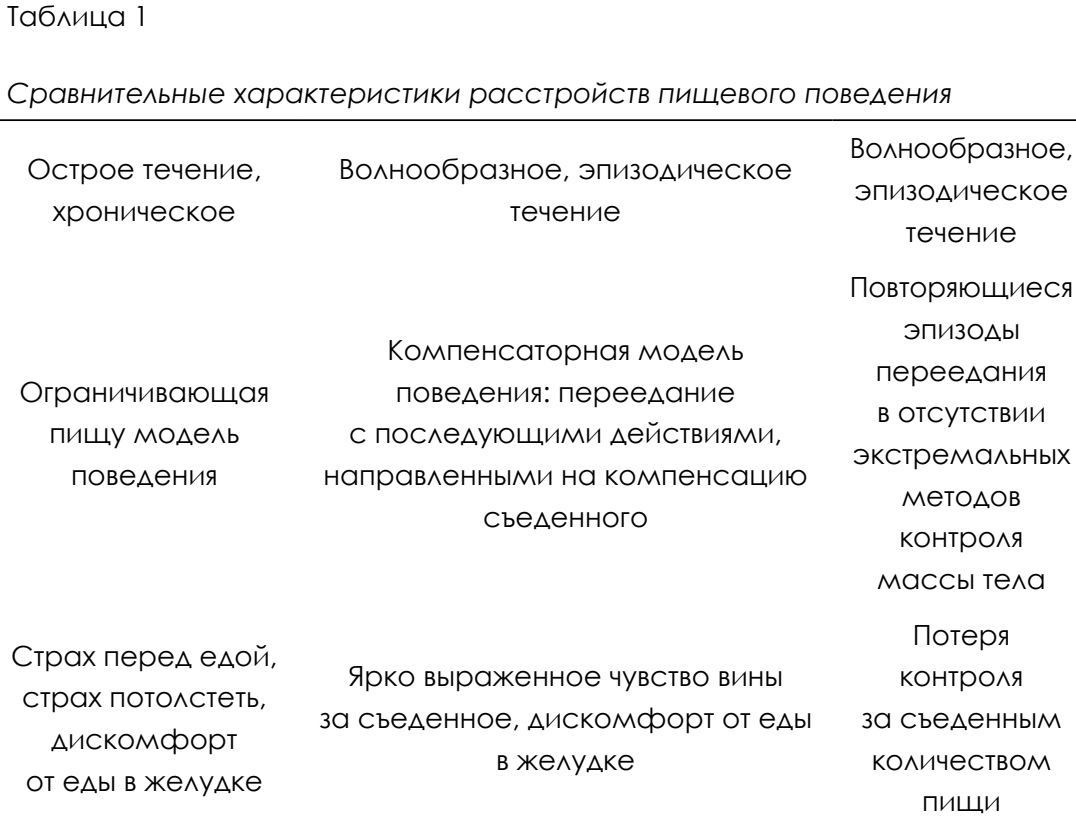

Острое течение, Волнообразное, эпизодическое хроническое течение

Компенсаторная молель

Ограничивающая пищу моАеАь поведения

Страх перел елой, страх потолстеть, Аискоморорт от еАы в желудке

поведения: переедание

с послеАующими Аействиями, направленными на компенсацию

сьеленного

Ярко выраженное чувство вины за съеленное, Аискомфорт от еды в желудке

Волнообразное, эпизодическое течение

Повторяющиеся эпизоАы переелания в отсутствии экстремальных метоАОв контроля мaссы тела

Потеря контро^я за сьеленным количеством пищи

Причиной развития булимии становятся, например, давление со стороны родителей, стремление к перфекционизму и идеалу, деструктивная критика, которая занижала детскую самооценку. Люди, страдающие булимией, зачастую негативно высказываются в отношении обоих родителей. Они могут жаловаться на недостаток внимания или жестокое обращение, эмоциональное насилие в семье (Панюкова, 2019).

Так, в одном из исследований анализировалось влияние жестокого эмоционального обращения с детьми в качестве фактора, повышающего риск развития булимического синдрома (Vajda \& Láng, 2014). В исследовании подчеркивается важность разделения физического, сексуального и эмоционального насилия в семье. Авторы утверждают, что эмоциональное насилие также является предиктором ряда психических проблем, которые оказывают влияние на самооценку и имеют прямую связь с чувством неполноценности и беспомощности. Тело больным представляется как одна из немногих сфер жизни, которую они в силах контролировать. В этом исследовании еще раз подчеркивается регулятивная в отношении эмоций функция приступов переедания. Таким образом, подчеркиваются два аспекта приступов переедания: 
1) чрезмерное потребление пищи позволяет отвлечься от негативных эмоций и дарит кратковременное чувство комфорта;

2) очищающее поведение символизирует собой контроль, способ самосогласования.

В свою очередь, изучение авторами опыта эмоционального насилия и его влияния на развитие булимического синдрома привело к следующим результатам: травматический опыт населения, страдающего расстройствами пищевого поведения, всё-таки является одним из существенных факторов развития патологического поведения. Результаты, полученные авторами исследования, также подтвердили выдвинутую ими гипотезу о связи между дефицитом регуляции эмоций и симптомами расстройства пищевого поведения. Ранее эта гипотеза также подтверждалась другими исследованиями.

Полученные данные можно сравнить с предыдущим, анализируемым нами исследованием, в котором изучалось влияние самосострадания на принятие решения «переедать - не переедать». В качестве надежного последствия эмоционального насилия в семье выделено плохое психическое здоровье. Эмоциональное насилие угнетает самооценку. В совокупности последствием может стать личность, неспособная к описанию своих эмоций (Goldsmith \& Freyd, 2005) и потому испытывающая каждый раз напряжение во время чувствования любых (и положительных и отрицательных) эмоциональных импульсов.

В качестве симптомов нервной булимии также выделяют чрезмерное чувство вины за съеденную пищу, глубокую депрессию и отсутствие самоконтроля (Солодовник и Неповинных, 2020).

\section{Изучение осознанности и импульсивности выбора стратегии пе- реедания в качестве эмоциональной компенсации}

Направлено ли, осознано ли переедание, предшествующее компенсаторному поведению? Некоторые исследования допускают гипотезу, согласно которой эпизоды срывов при нервной булимии изначально целенаправлены, но, в конечном счете, становятся более импульсивными, привычными и нечувствительными к негативным результатам (Berner et. al., 2020).

О.А. Скугаревский в монографии «Расстройства пищевого поведения» указывает, что переедание может заранее планироваться больными: «многие женщины с НБ сообщают о своеобразном парадоксальном контроле потребления пищи, когда эпизод переедания пунктуально планируется» (Скугаревский, 2007, с. 100). В свою очередь, поведение частично подконтрольно пациентам, и переедание зачастую останавливается из-за изменения внешних обстоятельств.

Таким образом, переедание заведомо осознано и выступает в качестве протеста долгому недоеданию, т. е. эпизоду, когда индивид с синдромом НБ 
придерживается «правильного» питания. В свою очередь, эпизод недоедания накапливает негативные эмоции. Развитие синдрома предположительно происходит по следующей траектории:

1. Человек встречается с социальным воздействием: культурной пропагандой идеального тела. И обнаруживает собственную неидеальность, несоответствие пропагандируемой эстетике.

2. Чтобы соответствовать этим нормам, идеалам и ценностям, индивид принимает решение самому влиять на свое тело диетами, тренировками и т.д.

3. Для того чтобы быстро достигнуть результата, используются крайние меры: сильное снижение калорийности рациона, чрезмерные тренировки, голод.

4. Это влечет за собой «срывы», после которых человек, естественно, набирает вес и испытывает чувство отчаяния, разочарования, поскольку все его труды потеряли всякий смысл.

5. Ключевым моментом является также своего рода «приобщение». С помощью Интернета или от знакомых индивид узнает, что можно вовремя избавиться от съеденного и, таким образом, не набрать вес.

6. Компенсаторное поведение - очищение с помощью рвоты - впервые осознанно принимается индивидом. Пробуя вызвать рвоту в первый раз, индивид может испытывать проблемы. Но и это не становится помехой, что еще раз указывает на тенденцию от осознанного к автоматическому.

7. После срыва, как ожидаемо, индивид не набирает вес, отчего не испытывает чувства разочарования и потери смысла своей основной деятельности на данный момент - похудения, что подкрепляет такое поведение.

8. В течение жизни индивид испытывает широкий спектр эмоций, которые пробуждают чувство голода. Сильный голод, в свою очередь, служит предиктором переедания.

9. Впоследствии данная стратегия поведения используется индивидом для избегания последствий переедания, которые имеют эмоциогенный характер.

10. Принятый осознанно выбор перетекает в автоматическую, привычную модель поведения как регулятора эмоциональных импульсов. В последующем индивид может прибегать к перееданию и очищению уже без видимой на то причины, т. е. привычно, автоматически. Очищение становится привычным завершением дня, без которого ощущается некоторая незавершенность, создающая, в свою очередь, новое эмоциональное напряжение. 


\section{Анализ исследований эмоциональных состояний больных нервной булимией}

Исследования пациентов с синдромом НБ подтверждают гипотезу о том, что рецидивы или «запойное поведение» сопровождаются определенными эмоциональными процессами и состояниями. По данным источников, чаще всего с помощью методик самоопределения, рефлексии и наблюдения психолога наблюдаются состояния тревоги, напряженности, депрессии и навязчивые страхи (Самсонова, 2015).

В этом плане НБ имеет сходство с признаками обсессивно-компульсивного расстройства (ОКР) и некоторыми авторами описывается как вариант проявления компульсии (Голубицкий, 2004). Получается, что переедание вызвано сильными эмоциональными импульсами, которые выводят индивида из состояния равновесия и требуют компенсации. И если индивид не испытывает негативные эмоции, но модель поведения «переедание - очищение» стала привычной, то источником напряжения становится отсутствие переедания.

В одном из исследований представлен типичный клинический случай нервной булимии (Bulik, Marcus, Zerwas, Levine, \& La Via, 2012). Пациентка «госпожа Z» утверждала, в подтверждение предыдущей гипотезы, что переедание служит для нее инструментом самоуспокоения. Стоит отметить, что женщина находилась в состоянии постоянного само- и социального контроля. У нее была ответственная работа, связанная со сферой образования, в частности, с университетом, и отнимавшая подавляющую часть времени ее жизни. По словам пациентки, у нее мало знакомых и еще меньше друзей. Она на протяжении последних пяти лет не была в романтических отношениях. Ее убеждение было построено на вере в то, что отношения с противоположным полом постоянно будут требовать от нее определенной самоотдачи, в то время как еда «всегда рядом, когда это нужно». Госпожа Z также не прибегала к другим способам регулирования эмоций: она не употребляла алкоголь и не курила. Ее жизнь циклична: она оставалась вечерами дома, чтобы съесть всю еду в холодильнике, а после искусственно вызывала рвоту, плакала и засыпала.

Изучалось также и влияние определенных эмоциональных состояний на протекание «срыва». В исследовании Serpell, Amey, \& Kamboj (2020) авторы выделяли в качестве факторов, сдерживающих чрезмерное потребление пищи у больных, такие эмоции, как самосострадание и самокритическое размышление. Очевидно, здесь также изучалось размышление в контексте индукции негативного настроения (чувства вины) на реактивность пищевого сигнала, аффект и потребление пищи. Авторами была выдвинута гипотеза, согласно которой стратегия самосострадания может снижать тягу к еде после еды, а также общее потребление пищи и, таким образом, исключает переедание. 
Результатами исследования подтверждается гипотеза об эффективности «наблюдения со стороны» и проявления сочувствия к себе во время актов переедания. Было замечено, что поощрение самосострадательного отношения к себе среди пациентов с расстройствами пищевого поведения уменьшает их желание переедать. Самосострадание снижает оценку положительного, приятного эмоционального эффекта пищи, по сравнению со стратегией самокритики. В свою очередь, последняя проявляется как самобичевание, критика отклоняющегося поведения. Получается, что подавление чувства вины способно предотвращать срыв.

Таким образом, переедание в любом случае вызвано и сопровождается эмоциональными состояниями. У пациентов с синдромом НБ негативное эмоциональное состояние часто наблюдается как перед, так и после переедания до эпизода очищения. Полной разрядкой служат лишь переедание и очищение как целостный механизм эмоциональной регуляции.

\section{Эмоционально-регулятивная функция переедания}

Рецидив (непосредственно переедание и очищение) выполняет регуляторную функцию - он способствует нормализации эмоционального фона, используется пациентами в качестве компенсации негативных эмоций. Рецидивы НБ связаны с переживаниями скуки, тревоги и печали, грусти. «Возникновению булимического приступа переедания часто предшествует появление и нарастание внутреннего напряжения и эмоционального дискомфорта» (Матвеев, 2008, с. 39).

Один из случаев нервной булимии, приведенных О. А. Скугаревским, иллюстрирует сильную озабоченность весом вплоть до самовнушения невозможных, логически легко опровергаемых закономерностей. Пациентка во время реабилитации считала, что съеденное ею сладкое печенье сразу же ощущается. Она буквально чувствует, «как распухают ее жировые клетки». Во время психотерапии специалисту пришлось наглядно показывать листы мониторинга. Предлагалось подумать над причиной покалывания, предполагаемого «распирания» в местах, где обычно скапливается жир. В ходе терапии пациентка призналась, что причина не в домашней выпечке, а непосредственно в самобичевании и боязни набрать лишние килограммы.

Следующее исследование, подтверждающее регулятивную функцию приступов нервной булимии (Mandich et. al., 2014) в качестве регулятора эмоций, проводилось на 6 пациентах с диагнозом «нервная булимия». Пациенты, которые использовали пищу в качестве компенсации негативных эмоций, отмечали, что предикторами рецидивов являются эмоции беспокойства, грусти и печали. В то же время другие 4 испытуемых утверждали, что используют акт поглощения еды как приятный процесс, но, отмечали, что только в случае 
последующего очищения. Как результат, облегчение наступало только в результате очищения. Тело выступало как объект, отличный от пациента (либо полностью ему безразличный), который контролируется человеком с помощью слабительных, правильного сочетания продуктов, спорта и рвоты. Эмоционально-регуляторная функция приступов булимии выполнялась больше за счет очищения, а не поедания пищи. Полученные результаты исследования можно сравнить с предыдущими, в которых было подчеркнуто, что пища выступает в качестве компенсации негативных эмоций. Беспокойство, грусть и печаль - отрицательно окрашенные эмоциональные импульсы. В свою очередь, желание получить положительно заряженные - расслабление, облегчение - тоже выступает эмоциональным аспектом. В поведении больного нервной булимией акт поглощения пищи не заканчивается только перееданием, но и обязательно включает в себя компенсацию.

Действия, направленные на предотвращение переедания и компенсаторного поведения, будут иметь большую эффективность в момент, предшествующий перееданию, а не очищению. Тем самым, если заменить переедание на другой вид деятельности (творчество и т. д.), можно предотвратить компенсаторное поведение. Воздействия, направленные на разрыв цепочки «переедание - очищение», будут наиболее эффективными перед перееданием, нежели после него. Если переедание выступает специфическим регулятором эмоционального состояния, то полезным может оказаться введение новых способов регулирования эмоций.

\section{Результаты и их обсуждение}

Таким образом, поведение больного нервной булимией сопровождается определенными эмоциональными процессами и состояниями, среди которых чаще всего фигурируют: тревога, беспокойство, грусть, страх, неуверенность, стресс и т. д. Переедание нередко выступает как специфический регулятор эмоциональных импульсов. Приступ является способом «расслабиться, избавиться от негативных эмоций, ощутить чувство комфорта» и, в то же время, играет функцию своеобразного «контроля и способа самосогласования».

При сравнении людей с синдромом нервной булимии и с другими расстройствами пищевого поведения, было выявлено, что они не обладают большей импульсивностью. Это черта скорее класса расстройств, нежели непосредственно нервной булимии. Контроль также является одним из факторов успешной реабилитации. В исследованиях не раз отмечена эффективность внушения, целеполагания и самоконтроля. Получается, что самоконтроль, наоборот, выступает фактором, способствующим подавлению переедания.

Индивид с синдромом НБ частично осознанно делает выбор не перед компенсаторным поведением (в отношении съеденной еды, компенсации 
калорий), а непосредственно перед перееданием. Избавиться от негативных эмоций или стресса можно с помощью других видов деятельности: творчества, медитации и т. д. Особенностью еды в качестве регулятора эмоциональных состояний становится то, что описано в исследовании клинического случая «госпожи Z»- доступность пищи. В связи с доступностью еды, использование ее в качестве регулятора эмоциональных состояний становится привычным.

В жизни человека с синдромом нервной булимии устанавливается определенная цикличность:

1. Эпизод ограничений. Из-за ограничений в еде индивид испытывает накапливающиеся негативные эмоции и стресс. Характерен самоконтроль. Идеей для индивида выступают здоровый образ жизни, правильное питание.

2. Выбор. В определенный момент, когда негативные эмоции и стресс накапливаются в достаточной мере, человек испытывает потребность компенсировать свое эмоциональное состояние. В этот момент перед ним встает выбор способа регуляции.

3. Переедание - регуляция негативных эмоций, стресса от диеты. Во время поглощения пищи испытывается «разрядка», «расслабление». В это время становятся безразличными волнующие ранее обстоятельства.

4. Эпизод компенсации переедания. Последующее за актом переедания компенсаторное поведение: самопроизвольная рвота, интенсивные физические нагрузки, прием слабительных или мочегонных средств. Характерные эмоции: чувство вины, подавленности, страх набрать вес.

Непосредственно переедание и компенсаторное поведение выступают как целостный механизм компенсации недостатка пищи. Переедание без компенсаторного поведения - это стрессогенное, эмоциогенное переедание, но не синдром НБ. Если индивид оказывается в положении, когда не может из-за каких-то обстоятельств переесть и компенсировать съеденную пищу, то может значительно снижаться вероятность срыва.

В свою очередь, переедание служит механизмом регуляции как эмоций, так и физиологического дисбаланса вследствие неправильной диеты. Если препятствовать уже привычному перееданию, то можно препятствовать и компенсаторному поведению, которое неразрывно за ним следует.

\section{Заключение}

Компенсаторное поведение больных нервной булимией является угрозой жизни как с психологической, так и с физиологической точки зрения. Произвольная рвота опасна для ротовой полости и органов желудочно-кишечного тракта, нарушает внутренние обменные процессы и угнетает работу 
внутренних органов. Срывы также сопровождаются сильными негативными эмоциональными состояниями.

Одно из таких сильных эмоциональных состояний - чувство вины, которое наступает после переедания. В свою очередь, выявлено, что противоположное про направленности эмоциональное состояние - самосочувствие - снижает риск рецидива. Не менее важно, что в основе переедания тоже могут быть импульсивные эмоциональные переживания. Причем переедание служит способом саморегуляции.

Таким образом, можно сделать следующие выводы:

1. Жизнь человека с синдромом нервной булимии циклична: она включает в себя ограничения, принятие выбора, переедание и компенсацию. Если после переедания нет компенсации, то индивид испытывает еще большее угнетение, чем до него.

2. Особенностью нервной булимии очистительного типа, в отличие от других расстройств пищевого поведения, является компенсаторное поведение - рвота или прием слабительных и диуретиков, которое может быть предотвращено или заменено в определенный момент.

3. Переедание выступает в качестве специфического эмоционального регулятора.

Дальнейшее изучение регулирования эмоциональных состояний при нервной булимии позволит разработать эффективные методики для ее преодоления. Такие методики могут стать одним из значимых инструментов в практике психолога, работающего с расстройствами пищевого поведения.

\section{Литература}

Голубицкий, А. А. (2004). Маркетинг пациентов с непсихотическими формами депрессивных состояний. Сибирское медицинское обозрение, 2-3, 82-83.

Ильина, В. А. (2020). Идеализация расстройства пищевого поведения в виртуальном пространстве. Скиф. Вопросы студенческой науки, 4, 95-99.

Маслов, В. П., Гнатюк, М. А. и Самыгин, С. И. (2018). Сетевое сообщество: риски и угрозы Интернет-среды для киберсоциализации молодежи. Гуманитарные, социально-экономические и общественные науки, 8. https:// doi.org/10.23672/SAE.2018.2018.16562

Матвеев, А. А. (2008). Репрезентация эмоций у больных нервной булимией. Вестник Московского университета. Серия 14: Психология, 4, 38-53.

Медведев, В. П. и Лоскучерявая, Т. Д. (2013). Нервная анорексия и нервная булимия у детей и подростков: диагностика и лечение. Российский семейный врач, 17(1), 4-15. 
МЕДИЦИНСКАЯ ПСИХОЛОГИЯ

Международная статистическая классификачия болезней и проблем, связанных со здоровьем. Десятый пересмотр (2003). (М. В. Максимова, С. К. Чемякина, А. Ю. Сафронова, пер. с англ.). Москва: Медицина.

Мэйа, М., Халми, К., Лопез-Ибор, Х. Х. и Сарториус, Н. (2006). Расстройства пищевого поведения. Киев: Сфера.

Панькив, В. И. (2013). Ожирение. Международный эндокринологический журнал, 5, 150-156.

Панюкова, А. С. (2019). Социологические факторы возникновения расстройства пищевого поведения. Международный журнал гуманитарных и естественных наук, 4-2, 15-17. https://doi.org/10.24411/2500-1000-2019-10741

Самсонова, К. А. (2015). Нарушения пищевого поведения и регуляция эмоций. Акмеология, 3, 218.

Скугаревский, О. А. (2007). Нарушения пищевого поведения: монография. Минск: БГМУ.

Солодовник, Е. М. и Неповинных, Л. А. (2020). Современные представления молодежи о расстройствах пищевого поведения (булимия). Международный журнал гуманитарных и естественных наук, 3-1, 159-163. https://doi. org/10.24411/2500-1000-2020-10227

Berner, L., de Wit, S., Simmons, A., Marsh, R., Chen, J., Krueger, A., \& Kaye, W. (2020). Goal-directed and inhibitory control in women with bulimia nervosa. Biological Psychiatry, 87(9), S179. https://doi.org/10.1016/j.biopsych.2020.02.471

Bulik, C. M., Marcus, M. D., Zerwas, S., Levine, M. D., \& La Via, M. (2012). The changing "weightscape" of bulimia nervosa. The American Journal of Psychiatry, 169(10), 1031-1036. https://doi.org/10.1176/appi.ajp.2012.12010147

Goldsmith, R. E., \& Freyd, J. J. (2005). Awareness for emotional abuse. Journal of Emotional Abuse, 5(1), 95-123. https://doi.org/10.1300/J135v05n01_04

Hoek, H. W., \& van Hoeken, D. (2003). Review of the prevalence and incidence of eating disorders. International Journal of Eating Disorders, 34(4), 383-396. https://doi.org/10.1002/eat.10222

Mandich, C. C., Castrillón, F. D., Navarro, J. A., Troncoso, A. G., Astudillo, R. B., \& Meza, M. A. (2014). Speeches in anorexia and bulimia nervosa: A qualitative study about the disorder experiencing. Revista Mexicana de Trastornos Alimentarios, 5(2). https://doi.org/10.1016/S2007-1523(14)72002-6

Russell, G. (1979). Bulimia nervosa: An ominous variant of anorexia nervosa. Psychological Medicine, 9(3), 429-448. https://doi.org/10.1017/s0033291700031974

Serpell, L., Amey, R., \& Kamboj, S. K. (2020). The role of self-compassion and self-criticism in binge eating behaviour. Appetite, 144. https://doi.org/10.1016/j.appet.2019.104470

Simpson, S. G., Al-Mufti, R., Andersen, A. E., \& DePaulo, J. R. Jr. (1992). Bipolar Il affective disorder in eating disorder inpatients. The Journal of Nervous and Mental Disease, 180(11), 719-722. https://doi.org/10.1097/00005053-199211000-00006 
Vajda, A., \& Láng, A. (2014). Emotional abuse, neglect in eating disorders and their relationship with emotion regulation. Procedia - Social and Behavioral Sciences, 131, 386-390. https://doi.org/10.1016/j.sbspro.2014.04.135

\section{References}

Berner, L., de Wit, S., Simmons, A., Marsh, R., Chen, J., Krueger, A., \& Kaye, W. (2020). Goal-directed and inhibitory control in women with bulimia nervosa. Biological Psychiatry, 87(9), S179. https://doi.org/10.1016/j.biopsych.2020.02.471

Bulik, C. M., Marcus, M. D., Zerwas, S., Levine, M. D., \& La Via, M. (2012). The changing "weightscape" of bulimia nervosa. The American Journal of Psychiatry, 169(10), 1031-1036. https://doi.org/10.1176/appi.ajp.2012.12010147

Goldsmith, R. E., \& Freyd, J. J. (2005). Awareness for emotional abuse. Journal of Emotional Abuse, 5(1), 95-123. https://doi.org/10.1300/J135v05n01 04

Golubitskii, A. A. (2004). Marketing of patients with non-psychotic forms of depression. Siberian Medical Review, 2-3, 82-83. (in Russ.).

Hoek, H. W., \& van Hoeken, D. (2003). Review of the prevalence and incidence of eating disorders. International Journal of Eating Disorders, 34(4), 383-396. https://doi.org/10.1002/eat.10222

Ilina, V. (2020). The idealization of eating disorders in the virtual space. Skif. Voprosy studencheskoi nauki, 4, 95-99. (in Russ.).

International statistical classification of diseases and related health problems. Tenth revision (2003). (M. V. Maksimova, S. K. Chemyakina, A. Yu. Safronova, Trans.). Moscow: Meditsina. (in Russ.).

Maj, M., Halmi, K., López Ibor, J. J., \& Sartorius, N. (2006). Eating disorders. Kiev: Sfera. (in Russ.).

Mandich, C. C., Castrillón, F. D., Navarro, J. A., Troncoso, A. G., Astudillo, R. B., \& Meza, M. A. (2014). Speeches in anorexia and bulimia nervosa: A qualitative study about the disorder experiencing. Revista Mexicana de Trastornos Alimentarios, 5(2). https://doi.org/10.1016/S2007-1523(14)72002-6

Maslov, V. P., Gnatyuk, M. A., \& Samygin, S. I. (2018). Network community: Risks and dangers of the Internet environment for the cybersocialization of youth. Humanities, Social-Economic and Social Sciences, 8. https://doi.org/10.23672/ SAE.2018.2018.16562 (in Russ.).

Matveyev, A. A. (2008). Representation of emotions with patients suffering from bulimia nervosa. Moscow University Psychology Bulletin. Series 14. Psychology, 4, 38-53. (in Russ.).

Medvedev, V. P., \& Loskucheryavaya, T. D. (2013). Anorexia nervosa and bulimia nervosa in children and adolescents: diagnostic and treatment. Russian Family Doctor, 17(1), 4-15. (in Russ.).

Pankiv, V. I. (2013). Obesity. International Journal of Endocrinology, 5, 150-156. (in Russ.). 
МЕДИЦИНСКАЯ ПСИХОЛОГИЯ

Panyukova, A. S. (2019). Sociological factors of emergency disorder of food behavior. International Journal of Humanities and Natural Sciences, 4-2, 15-17. https://doi.org/10.24411/2500-1000-2019-10741 (in Russ.).

Russell, G. (1979). Bulimia nervosa: An ominous variant of anorexia nervosa. Psychological Medicine, 9(3), 429-448. https://doi.org/10.1017/ $\underline{\mathrm{s} 0033291700031974}$

Samsonova, K. A. (2015). Eating disorders and emotional regulation. Akmeologiya (Acmeology), 3, 218. (in Russ.).

Serpell, L., Amey, R., \& Kamboj, S. K. (2020). The role of self-compassion and selfcriticism in binge eating behaviour. Appetite, 144. https://doi.org/10.1016/j. appet.2019.104470

Simpson, S. G., Al-Mufti, R., Andersen, A. E., \& DePaulo, J. R. Jr. (1992). Bipolar Il affective disorder in eating disorder inpatients. The Journal of Nervous and Mental Disease, 180(11), 719-722. https://doi.org/10.1097/00005053-199211000-00006

Skugarevskii, O. A. (2007). Eating disorders: Monograph. Minsk: Belarusian State Medical University. (in Russ.).

Solodovnik, EAT., \& Innocent, L. A. (2020). Modern representations of youth about disorders of food behavior (bulimia). International Journal of Humanities and Natural Sciences, 3-1, 159-163. https://doi.org/10.24411/2500-1000-202010227 (in Russ.).

Vajda, A., \& Láng, A. (2014). Emotional abuse, neglect in eating disorders and their relationship with emotion regulation. Procedia - Social and Behavioral Sciences, 131, 386-390. https://doi.org/10.1016/j.sbspro.2014.04.135

Конфрликт интересов отсутствует

Аата получения рукописи: 20.02.2021

Аата окончания рецензирования: 05.03.2021

Аата принятия к публикации: 11.03 .2021 